\title{
An Exhaustive Study of Possibility Measures of Interval-Valued Intuitionistic Fuzzy Sets and Application to Multicriteria Decision Making
}

\author{
Fatma Dammak, Leila Baccour, and Adel M. Alimi \\ REGIM-Lab.: Research Groups in Intelligent Machines, University of Sfax, ENIS, BP 1173, 3038 Sfax, Tunisia \\ Correspondence should be addressed to Fatma Dammak; fatma.dammak.tn@ieee.org
}

Received 14 April 2016; Revised 7 June 2016; Accepted 9 June 2016

Academic Editor: Rustom M. Mamlook

Copyright (C) 2016 Fatma Dammak et al. This is an open access article distributed under the Creative Commons Attribution License, which permits unrestricted use, distribution, and reproduction in any medium, provided the original work is properly cited.

This work is interested in showing the importance of possibility theory in multicriteria decision making (MCDM). Thus, we apply some possibility measures from literature to the MCDM method using interval-valued intuitionistic fuzzy sets (IVIFSs). These measures are applied to a decision matrix after being transformed with aggregation operators. The results are compared between each other and concluding remarks are drawn.

\section{Introduction}

Multicriteria decision making methods have been developed widely using fuzzy sets and their generalizations. Park et al. [1] extended TOPSIS method for decision making problems under interval-valued intuitionistic fuzzy environment. Park et al. [2] generalized the concepts of correlation coefficient of intuitionistic fuzzy sets into interval-valued intuitionistic fuzzy sets. Ye [3] proposed weighted correlation coefficients using entropy weights under interval-valued intuitionistic fuzzy environment to rank alternatives. Zhang and Yu [4] extended TOPSIS method using cross entropy and generalized an MCMD approach with interval-valued intuitionistic fuzzy sets. The possibility theory has also been applied in many research topics. To rank alternatives, a comparison between the obtained matrix and aggregated IVIFS is mandatory. This is applied by an accuracy function in [5-8] or a possibility measure. To apply possibility measures to a decision matrix of IVIFS, an aggregation is needed. Some aggregation methods under interval-valued intuitionistic fuzzy information are given in $[7,9,10]$. In the same way, $\mathrm{Xu}$ in $[11,12]$ developed some aggregation operators: intuitionistic fuzzy weighted averaging operator, intuitionistic fuzzy ordered weighted averaging (IFOWA), intuitionistic fuzzy weighted averaging (IFWA) operator, and intuitionistic fuzzy hybrid aggregation (IFHA) operator. Wei and Tang [13] extended the possibility method of intervalvalued numbers defined by $[14,15]$ to intuitionistic fuzzy sets [16] and defined a possibility formula to compare two intuitionistic fuzzy numbers (IFNs). In addition, Xu and $\mathrm{Da}$ [14] presented a possibility formula to compare two interval fuzzy numbers and applied possibility measures of intervalvalued intuitionistic fuzzy numbers to multicriteria decision making. Gao [17] presented four possibility measures and proved their equivalence. Liu and Lv [18] used possibility measures for the ranking of interval fuzzy numbers.

Our aim is to present and compare several possibility measures under intuitionistic fuzzy and interval-valued intuitionistic fuzzy environment. The remaining of this paper is organized as follows: in Section 2, the possibility theory and measures of IFS are detailed. In Section 3, some preliminaries about IVIFS and the possibility measures are introduced. In Section 4, an IVIF MCDM method is adopted. In Section 5, aggregation operators and possibility measures are applied and their results are compared. In Section 6, the conclusion is drawn.

\section{Possibility Theory}

The possibility theory, proposed by Zadeh [19], defines a pair of dual set functions: possibility and necessity measures. Therefore a possibility degree $\Pi(u)$ quantifies the extent 
an event $u$ is plausible, and the necessity degree $N(u)$ quantifies the certainty of $u$. The model of imperfect data in the possibility theory is the possibility distribution $\pi_{B(x)} \epsilon$ $[0,1]$ which characterizes the uncertain membership of an element $x$ in a (well-defined) known class $B$.

(i) $\prod(A)=\max _{u \in A} \pi(b)$ : the possibility degree that $u \in$ A.

(ii) $N(A)=1-\prod(\bar{A})=\min _{u \notin A} 1-\pi(b)$ : the certainty degree (necessity) that $u \in A$ and $\bar{A}$ complement of event $A$.

Then the possibility distribution $\pi$ can be easily recovered from the possibility measure $\prod$.

(i) Possibility distribution: $\pi(u)=\inf _{A: u \in A} \prod(A)$.

(ii) Necessity measures: $N(A)=1-\prod(\bar{A})=\inf _{u \notin A} 1-$ $\pi(u)$. If $N(A)=1, A$ is certainly true, and if $N(A)=0$, $A$ is not certain ( $A$ is still possible).

2.1. Possibility Measures to Compare Intuitionistic Fuzzy Numbers (IFNs) Existing in Literature. The comparison between IFNs (see appendices) can be solved by using the possibility degree formula of the interval values. Thus the possibility measures have to satisfy the following properties [20].

Let $a=\left[a^{-}, a^{+}\right], b=\left[b^{-}, b^{+}\right]$, and $c=\left[c^{-}, c^{+}\right]$; then we have the following:

(i) $0 \leq p(a \geq b) \leq 1$;

(ii) complementary: $p(a \geq b)+p(b \geq a)=1$;

(iii) transitivity: if $p(a \geq b) \geq 0.5$ and $p(b \geq c) \geq 0.5$, then $p(a \geq c) \geq 0.5$

(iv) $p(a \geq b) \geq 0.5$, if and only if $a^{-}+a^{+} \geq b^{-}+b^{+}$;

(v) $p(a \geq b)=0.5$, if and only if $a^{-}+a^{+}=b^{-}+b^{+}$.

In what follows, we present the different formulas of possibility measures $p(a \geq b)$ with $a=\left[a^{-}, a^{+}\right]$and $b=\left[b^{-}, b^{+}\right]$ being two intuitionistic fuzzy numbers and $\pi(a)=1-a^{-}-a^{+}$, $\pi(b)=1-b^{-}-b^{+}$

(i) Yuan and $\mathrm{Qu}[20]$ presented some formulas to compare two interval numbers and denoted $l_{a}=a^{+}-a^{-}, l_{b}=$ $b^{+}-b^{-}$. The possibility measures of $p(a \geq b)$ are presented as follows:

Definition 1 [21]:

$$
p(a \geq b)=\min \left\{\max \left(\frac{a^{+}-b^{-}}{l_{a}+l_{b}}, 0\right), 1\right\} .
$$

Definition 2 [22]:

$$
p(a \geq b)=\frac{\max \left\{0, l_{a}+l_{b}-\max \left(b^{+}-a^{-}\right)\right\}}{l_{a}+l_{b}} .
$$

Definition 3 [23]:

$$
p(a \geq b)=\frac{\min \left\{l_{a}+l_{b}, \max \left(a^{+}-b^{-}, 0\right)\right\}}{l_{a}+l_{b}} .
$$

In $[14,17]$, the authors have proved the equivalence of the above three formulas. In [20] these formulas are used to compare two countries. Reference [18] used possibility degree formula (3) to rank interval rough numbers.

(ii) In $[4,24,25]$, the authors defined the possibility measures and called them likelihood measures as follows:

$$
\begin{aligned}
& p(a \geq b)=\max \left\{1-\max \left(\frac{b^{+}-a^{-}}{l_{a}+l_{b}}, 0\right), 0\right\}, \\
& p(b \geq a)=\max \left\{1-\max \left(\frac{a^{+}-b^{-}}{l_{a}+l_{b}}, 0\right), 0\right\},
\end{aligned}
$$

where $l_{a}=a^{+}-a^{-}$and $l_{b}=b^{+}-b^{-}$.

(iii) In [15] the possibility measure is shown as follows:

$$
p(a \geq b)=\frac{\max \left(0, a^{+}-b^{-}\right)-\max \left(0, a^{-}-b^{+}\right)}{\left(a^{+}-a^{-}\right)+\left(b^{+}-b^{-}\right)} .
$$

(iv) Wei and Tang [13] generalized possibility measure of interval-valued numbers to intuitionistic fuzzy sets.

If $\pi(a)$ and $\pi(b)$ are different from zero, the possibility measure of $a \geq b$ is

$$
\begin{aligned}
p(a>b)= & \frac{\max \left\{0,\left(a^{-}+\pi(a)\right)-b^{-}\right\}}{\pi(a)+\pi(b)} \\
& -\frac{\max \left\{0, a^{-}-\left(b^{-}+\pi(b)\right)\right\}}{\pi(a)+\pi(b)} .
\end{aligned}
$$

(v) Gao [17] presented some formulas of possibility (1), (2), (4), and (8) and proved their equivalence:

$$
\begin{aligned}
& p_{3}(a \geq b) \\
& = \begin{cases}1 & b^{+}<a^{-} \\
\frac{a^{+}-b^{-}}{\left(a^{+}-a^{-}\right)+\left(b^{+}-b^{-}\right)} & b^{-} \leq a^{+}, a^{-} \leq b^{+} \\
0 & b^{-}>a^{+} .\end{cases}
\end{aligned}
$$

(vi) Gao [17] determined the equivalence between formulas (1), (2), (4), and (8) and integrated the following possibility measures:

(a) The first formula [26]:

$$
\begin{aligned}
& p(a \geq b)=\frac{1}{2}\left(1+\frac{\left(a^{+}+b^{+}\right)+\left(a^{-}-b^{-}\right)}{\left|a^{+}-b^{+}\right|+\left|a^{-}-b^{-}\right|+l_{a b}}\right), \\
& \text { where } l_{a b}=\left|a^{+}-a^{-}\right|+\left|b^{+}-b^{-}\right| .
\end{aligned}
$$

(b) The second formula [27]:

$$
\begin{aligned}
& p(a \geq b) \\
& \quad= \begin{cases}1 & b^{+} \leq a^{-} \\
\frac{\left(a^{+}-b^{-}\right)^{2}}{\left(a^{+}-b^{-}\right)^{2}+\left(b^{+}-a^{-}\right)^{2}} & b^{-}<a^{+}, a^{-}<b^{+} \\
0 & b^{-} \geq a^{+} .\end{cases}
\end{aligned}
$$


(c) Results of integrated formulas (9) and (10):

$$
\begin{aligned}
& p(a \geq b) \\
& \quad= \begin{cases}1 & b^{+} \leq a^{-} \\
\frac{\left(a^{+}-b^{-}\right)^{2}}{2\left(a^{+}-a^{-}\right)\left(b^{+}-b^{-}\right)} & a^{-}<b^{-} \leq a^{+}<b^{+} \\
1-\frac{\left(b^{+}-a^{-}\right)^{2}}{2\left(a^{+}-a^{-}\right)\left(b^{+}-b^{-}\right)} & b^{-}<a^{-} \leq b^{+}<a^{+} \\
\frac{a^{-}+a^{+}-2 b^{-}}{2\left(b^{+}-b^{-}\right)} & b^{-} \leq a^{-} \leq a^{+} \leq b^{+} \\
\frac{2 a^{+}-b^{+}-b^{-}}{2\left(a^{+}-a^{-}\right)} & a^{-} \leq b^{-} \leq b^{+} \leq a^{+} \\
0 & b^{-} \geq a^{+} .\end{cases}
\end{aligned}
$$

(vii) According to Chen [28], the possibility measure of the event $a \geq b$ is presented as follows:

$$
p(a \geq b)=\max \left\{1-\max \left\{\frac{\left(1-b^{+}\right)-a^{-}}{l_{1}+l_{2}}, 0\right\}, 0\right\},
$$

where $l_{1}=1-a^{-}-a^{+}$and $l_{2}=1-b^{-}-b^{+}$.

\section{Interval-Valued Intuitionistic Fuzzy Sets}

There are some basic concepts related to the interval-valued intuitionistic fuzzy sets (IVIFS) [29]. Let $X=\left\{x_{1}, x_{2}, \ldots, x_{n}\right\}$ be a nonempty set of the universe. An IVIFS $\widetilde{A}$ is defined as $\widetilde{A}=\left\{\left\langle x_{i},\left[\mu_{\widetilde{A}}^{L}\left(x_{i}\right), \mu_{\widetilde{A}}^{U}\left(x_{i}\right)\right],\left[\nu_{\widetilde{A}}^{L}\left(x_{i}\right), \nu_{\widetilde{A}}^{U}\left(x_{i}\right)\right]\right\rangle \mid x_{i} \in X\right\}$, where $\left[\mu_{\widetilde{A}}^{L}\left(x_{i}\right), \mu_{\widetilde{A}}^{U}\left(x_{i}\right)\right]$ and $\left[\nu_{\widetilde{A}}^{L}\left(x_{i}\right), \nu_{\widetilde{A}}^{U}\left(x_{i}\right)\right]$ denote the intervals of the membership degree and nonmembership degree of the element $x_{i} \in \widetilde{A}$, satisfying the following:

(i) $\mu_{\widetilde{A}}^{U}\left(x_{i}\right)+\nu_{\widetilde{A}}^{U}\left(x_{i}\right) \leq 1$,

(ii) $0 \leq \nu_{\widetilde{A}}^{L}\left(x_{i}\right) \leq \nu_{\widetilde{A}}^{U}\left(x_{i}\right) \leq 1$ and $\mu_{\widetilde{A}}^{L}\left(x_{i}\right) \leq \mu_{\widetilde{A}}^{U}\left(x_{i}\right)$ for all $x_{i} \in X$,

(iii) if $\mu_{\widetilde{A}}^{L}\left(x_{i}\right)=\mu_{\widetilde{A}}^{U}\left(x_{i}\right)$ and $\nu_{\widetilde{A}}^{L}\left(x_{i}\right)=\nu_{\widetilde{A}}^{U}\left(x_{i}\right)$, then $\widetilde{A}$ is reduced to an IFS.

3.1. Aggregation Operators Existing in Literature. The aggregation operators are necessary to reduce the IVIFS values; thus, we can compare them using an accuracy function or a possibility measure. In the following, we present two existing aggregation operators.

(i) $\mathrm{Xu}$ and Wei $[6,30]$ defined the interval-valued intuitionistic fuzzy weighted geometric (IVIFWG) operator as follows:

$$
\begin{aligned}
& \operatorname{IVIFWG}_{w}\left(\widetilde{\alpha_{1}}, \widetilde{\alpha_{2}}, \ldots, \widetilde{\alpha_{n}}\right) \\
& =\left(\left[\prod_{j=1}^{n}\left(a_{j}\right)^{w_{j}}, \prod_{j=1}^{n}\left(b_{j}\right)^{w_{j}}\right],\right. \\
& \\
& \left.\left[1-\prod_{j=1}^{n}\left(1-c_{j}^{w_{j}}\right), 1-\prod_{j=1}^{n}\left(1-d_{j}^{w_{j}}\right)\right]\right),
\end{aligned}
$$

where $w=\left(w_{1}, w_{2}, \ldots, w_{n}\right)^{T}$ is the weight vector of $\widetilde{\alpha_{j}}(j=$ $1,2, \ldots, n), w_{j} \in[0,1]$ and $\sum_{j=1}^{n} w_{j}=1$.

(ii) Wang et al. [9] defined the optimal aggregated interval-valued intuitionistic fuzzy sets using this formula:

$$
\widetilde{\alpha_{i}}=\left(\left[\sum_{j=1}^{n} a_{i j} w_{j}, \sum_{j=1}^{n} b_{i j} w_{j}\right],\left[\sum_{j=1}^{n} c_{i j} w_{j}, \sum_{j=1}^{n} d_{i j} w_{j}\right]\right) .
$$

3.2. Possibility Measures to Compare Interval-Valued Intuitionistic Fuzzy Number (IVIFN) Existing in Literature. Let $\widetilde{\alpha_{1}}=$ $\left(\left[a_{1}, b_{1}\right],\left[c_{1}, d_{1}\right]\right)$ and $\widetilde{\alpha_{2}}=\left(\left[a_{2}, b_{2}\right],\left[c_{2}, d_{2}\right]\right)$ be two intervalvalued intuitionistic fuzzy numbers in $\Omega$, which is the set of all IVIFNs $[2,5,31,32] \cdot p\left(\widetilde{\alpha_{1}} \geq \widetilde{\alpha_{2}}\right)$ is the possibility measure of two interval-valued intuitionistic fuzzy numbers. Let us present the existing possibility measures.

(i) Zhang et al. [7] defined two possibility measures of two interval-valued intuitionistic fuzzy numbers as follows:

(a) First measure:

$$
\begin{aligned}
p_{1} & \left(\widetilde{\alpha_{1}} \geq \widetilde{\alpha_{2}}\right) \\
& =\min \left(\max \left(A\left(\widetilde{\alpha_{1}}\right)-A\left(\widetilde{\alpha_{2}}\right)+0.5,0\right), 1\right),
\end{aligned}
$$

where $A\left(\widetilde{\alpha_{1}}\right)=\lambda((a+b) / 2)+(1-\lambda)((a-c+b-d) / 2)$ and $\lambda \in[0,1]$ which represents the performance on the mean value of its membership degree.

This possibility degree satisfies the following properties:

(1) $0 \leq p_{1}\left(\widetilde{\alpha_{1}} \geq \widetilde{\alpha_{2}}\right) \leq 1$;

(2) $p_{1}\left(\widetilde{\alpha_{1}} \geq \widetilde{\alpha_{2}}\right)=1 \Leftrightarrow A\left(\widetilde{\alpha_{1}}\right)-A\left(\widetilde{\alpha_{2}}\right) \geq 0.5$;

(3) $p_{1}\left(\widetilde{\alpha_{1}} \geq \widetilde{\alpha_{2}}\right)=0 \Leftrightarrow A\left(\widetilde{\alpha_{1}}\right)-A\left(\widetilde{\alpha_{2}}\right) \leq-0.5$;

(4) $p_{1}\left(\widetilde{\alpha_{1}} \geq \widetilde{\alpha_{2}}\right)+p_{1}\left(\widetilde{\alpha_{2}} \geq \widetilde{\alpha_{1}}\right)=1$.

(b) Second measure:

$$
\begin{aligned}
& p_{2}\left(\widetilde{\alpha_{1}} \geq \widetilde{\alpha_{2}}\right) \\
& =\gamma \min \left(\max \left(\frac{b_{1}-a_{2}}{b_{1}-a_{2}+b_{2}-a_{2}}, 0\right), 1\right) \\
& \quad+(1-\gamma) \min \left(\max \left(\frac{d_{2}-c_{1}}{d_{1}-c_{1}+d_{2}-c_{2}}, 0\right), 1\right),
\end{aligned}
$$

where $\gamma \in[0,1]$ gives the decision makers' preference on membership degree or nonmembership degree. When $\gamma \geq 0.5$ the decision maker is optimal whereas when $\gamma<0.5$ the decision maker is pessimistic. Then, the below properties are checked:

(1) $0 \leq p_{2}\left(\widetilde{\alpha_{1}} \geq \widetilde{\alpha_{2}}\right) \leq 1$;

(2) $p_{2}\left(\widetilde{\alpha_{1}} \geq \widetilde{\alpha_{2}}\right)=1 \Leftrightarrow b_{2} \leq a_{1}$ and $d_{1} \leq c_{2}$;

(3) $p_{2}\left(\widetilde{\alpha_{1}} \geq \widetilde{\alpha_{2}}\right)=0 \Leftrightarrow b_{1} \leq a_{2}$ and $d_{2} \leq c_{1}$;

(4) $p_{2}\left(\widetilde{\alpha_{1}} \geq \widetilde{\alpha_{2}}\right)+p_{2}\left(\widetilde{\alpha_{2}} \geq \widetilde{\alpha_{1}}\right)=1$. 
(ii) Wan and Dong [33] defined possibility measure by the following formula:

$$
\begin{aligned}
& p_{3}\left(\widetilde{\alpha_{1}} \geq \widetilde{\alpha_{2}}\right) \\
& \quad=\frac{1}{2}\left\{p\left(\left[a_{1}, b_{1}\right] \geq\left[a_{2}, b_{2}\right]\right)+p\left(\left[c_{2}, d_{2}\right] \geq\left[c_{1}, d_{1}\right]\right)\right\},
\end{aligned}
$$

where $p\left(\left[a_{1}, b_{1}\right] \geq\left[a_{2}, b_{2}\right]\right)$ and $p\left(\left[c_{2}, d_{2}\right] \geq\left[c_{1}, d_{1}\right]\right)$ can be calculated using (4).

(iii) Chen [28] defined a lower likelihood $L^{-}$and an upper likelihood $L^{+}$on IVIFSs as

$$
\begin{aligned}
& L^{-}\left(\widetilde{\alpha_{1}} \geq \widetilde{\alpha_{2}}\right) \\
& \quad=\max \left\{1-\max \left\{\frac{\left(1-c_{2}\right)-a_{1}}{l_{a_{1}}+l_{a_{2}}}, 0\right\}, 0\right\},
\end{aligned}
$$

where $l_{a_{1}}=1-a_{1}-d_{1}$ and $l_{a_{2}}=1-b_{2}-c_{2}$, and

$$
\begin{aligned}
& L^{+}\left(\widetilde{\alpha_{1}} \geq \widetilde{\alpha_{2}}\right) \\
& \quad=\max \left\{1-\max \left\{\frac{\left(1-d_{2}\right)-b_{1}}{l_{a_{1}}^{\prime}+l_{a_{2}}^{\prime}}, 0\right\}, 0\right\},
\end{aligned}
$$

where $l_{a_{1}}^{\prime}=1-b_{1}-c_{1}$ and $l_{a_{2}}^{\prime}=1-a_{2}-d_{2}$.

Then for two IVIFNs the likelihood $p_{4}\left(\widetilde{\alpha_{1}} \geq \widetilde{\alpha_{2}}\right)$ is defined as follows:

$$
p_{4}\left(\widetilde{\alpha_{1}} \geq \widetilde{\alpha_{2}}\right)=\frac{1}{2}\left(L^{-}\left(\widetilde{\alpha_{1}} \geq \widetilde{\alpha_{2}}\right)+L^{+}\left(\widetilde{\alpha_{1}} \geq \widetilde{\alpha_{2}}\right)\right)
$$

These measures are the same as those of the possibility measures.

\section{MCDM Based on Possibility Degree of Interval-Valued Intuitionistic Fuzzy Numbers}

For a multicriteria decision making problem, let $A=$ $\left\{A_{1}, A_{2}, \ldots, A_{n}\right\}$ be the set of alternatives and $X=$ $\left\{X_{1}, X_{2}, \ldots, X_{n}\right\}$ the set of criteria. $W=\left(w_{1}, w_{2}, \ldots, w_{n}\right)^{T}$ is the weight vector of criteria $X_{j}$, where $w_{j} \in[0,1]$ and $\sum_{j=1}^{n} w_{j}=1$

Suppose the characteristic information of alternative $A_{i}$ over criterion $X_{j}$ is represented by interval-valued intuitionistic fuzzy number $\widetilde{\alpha}=([a, b],[c, d])$, where $[a, b]$ represents the fuzzy membership degree of the alternative $A_{i}$ over criterion $X_{j}$ and $[c, d]$ represents the fuzzy nonmembership degree of the alternative $A_{i}$ over criterion $X_{j}$. Then the decision matrix $\widetilde{M}$ is obtained as

$$
\left(\begin{array}{ccc}
\left(\left[a_{11}, b_{11}\right],\left[c_{11}, d_{11}\right]\right) & \ldots & \left(\left[a_{1 m}, b_{1 m}\right],\left[c_{1 m}, d_{1 m}\right]\right) \\
\vdots & \vdots & \vdots \\
\left(\left[a_{n 1}, b_{n 1}\right],\left[c_{n 1}, d_{n 1}\right]\right) & \ldots & \left(\left[a_{n m}, b_{n m}\right],\left[c_{n m}, d_{n m}\right]\right)
\end{array}\right) .
$$

The ranking of the alternatives in the multicriteria decision making can be solved using the possibility measure of interval-valued intuitionistic fuzzy numbers. We chose to adopt a modified version of the method described in [4] following the steps below.

Step 1. Construct the interval-valued intuitionistic fuzzy decision matrix: $\widetilde{R}=\left(\widetilde{r}_{i j}\right)_{m \times n}=\left(\left[a_{i j}, b_{i j}\right],\left[c_{i j}, d_{i j}\right]\right)$.

Step 2. Calculate the intuitionistic fuzzy decision matrix $D_{i j}=\left[D_{i j}^{L}, D_{i j}^{U}\right]$ to derive $D_{i j}^{L}$ and $D_{i j}^{U}$, and $D_{i j}$ is the transformed IFN decision matrix obtained from $\widetilde{R}$ using formulas (22):

$$
\begin{aligned}
D_{i j}^{L} & =\frac{a_{i j} \ln 2+d_{i j} \ln \left(2 * d_{i j} / d_{i j}+1\right)+\ln \left(2 / d_{i j}+1\right)}{\left(a_{i j}+d_{i j}\right) \ln 2+a_{i j} \ln \left(2 a_{i j} / a_{i j}+1\right)+d_{i j} \ln \left(2 d_{i j} / d_{i j}+1\right)+\ln \left(2 / a_{i j}+1\right)+\ln \left(2 / d_{i j}+1\right)}, \\
D_{i j}^{U} & =\frac{b_{i j} \ln 2+c_{i j} \ln \left(2 * c_{i j} / c_{i j}+1\right)+\ln \left(2 / c_{i j}+1\right)}{\left(b_{i j}+c_{i j}\right) \ln 2+b_{i j} \ln \left(2 b_{i j} / b_{i j}+1\right)+c_{i j} \ln \left(2 c_{i j} / c_{i j}+1\right)+\ln \left(2 / b_{i j}+1\right)+\ln \left(2 / c_{i j}+1\right)} .
\end{aligned}
$$

Step 3. Assign weights to criteria; we use the following standard deviation (IF-SD) formula presented in [34] instead of that used in [4]:

$$
W_{j}=\frac{\sigma_{j}}{\sum_{j=1}^{n} \sigma_{j}}, \quad j=1, \ldots, n,
$$

where

$$
\begin{gathered}
\sigma_{j}=\sqrt{S\left(\mu_{i j}\right)+S\left(v_{i j}\right)}, \\
S\left(\mu_{i j}\right)=\frac{\sum_{i=1}^{m}\left(\mu_{i j}\left(C_{j}\right)-\overline{\mu_{j}}\left(C_{j}\right)\right)^{2}}{m}
\end{gathered}
$$

$$
\begin{aligned}
\overline{\mu_{j}}\left(C_{j}\right) & =\frac{\sum_{i=1}^{m} \overline{\mu_{i j}}\left(C_{j}\right)}{m}, \\
S\left(v_{i j}\right) & =\frac{\sum_{i=1}^{m}\left(v_{i j}\left(C_{j}\right)-\overline{v_{j}}\left(C_{j}\right)\right)^{2}}{m},
\end{aligned}
$$

where $\sum_{j=1}^{n} w_{j}=1$.

Step 4. Compute the performance of each alternative:

$$
D_{i}=\left[\sum_{j=1}^{n} W_{j} * D_{i j}^{L}, \sum_{j=1}^{n} W_{j} * D_{i j}^{U}\right] .
$$


Step 5. Compute the likelihood matrix [25]. To compare between tow interval fuzzy numbers, we propose to use a possibility measure instead of the formula used in [4] to obtain a possibility matrix. Therefore, each possibility measure presented in Section 2.1 is applied, and all the achieved results are compared in Section 5.

Step 6. Determine the alternatives ranking order, according to the decreasing order of $W_{i}[25]$ defined as

$$
W_{i}=\frac{\sum_{j=1}^{n} p_{i j}+m / 2-1}{m(m-1)}, \quad i=1,2, \ldots, m .
$$

\section{Illustrative Example}

5.1. Application of Possibility Measure of IFS in Decision Making Problem. This section described the data set presented in $[4,9]$ to evaluate the four potential investment opportunities $A=\{A 1, A 2, A 3, A 4\}$. The fund manager should evaluate each investment considering four criteria: risk $(C 1)$, growth (C2), sociopolitical issues (C3), and environmental impacts (C4). The fund manager is satisfied once he provides his assessment of each alternative on each criterion.

Step 1. The following interval-valued intuitionistic fuzzy sets (IVIFSs) decision making matrix (27) presents the relationship between criteria and alternatives of data set as follows:

$$
\left(\begin{array}{cccc}
{[0.42,0.48],[0.4,0.5]} & {[0.6,0.7],[0.05,0.25]} & {[0.4,0.5],[0.2,0.5]} & {[0.55,0.75],[0.15,0.25]} \\
{[0.4,0.5],[0.4,0.5]} & {[0.5,0.8],[0.1,0.2]} & {[0.3,0.6],[0.3,0.4]} & {[0.6,0.7],[0.1,0.3]} \\
{[0.3,0.5],[0.4,0.5]} & {[0.1,0.3],[0.2,0.4]} & {[0.7,0.8],[0.1,0.2]} & {[0.5,0.7],[0.1,0.2]} \\
{[0.2,0.4],[0.4,0.5]} & {[0.6,0.7],[0.2,0.3]} & {[0.5,0.6],[0.2,0.3]} & {[0.7,0.8],[0.1,0.2]}
\end{array}\right) \text {. }
$$

Each element of this matrix is presented with IVIFS, giving the fund manager's satisfaction or dissatisfaction degree with an alternative. The element represented for the first alternative $[0.42,0.48],[0.4,0.5]$, where the interval $42-$ $48 \%$ [4] reflects that the fund manager has an excellent opportunity to respect the risk criterion $(c 1)$, although the interval $40-50 \%$ does not really represent an excellent choice of $A 1$ for risk (c1).

Step 2. The intuitionistic fuzzy decision matrix (28) is obtained using (22):

$$
\left(\begin{array}{ccccc}
{[0.4452,0.5568]} & {[0.7458,0.9429]} & {[0.4304,0.7404]} & {[0.7220,0.8773]} \\
{[0.4304,0.5696]} & {[0.7404,0.9243]} & {[0.4172,0.7040]} & {[0.7040,0.9049]} \\
{[0.3494,0.5696]} & {[0.2229,0.5966]} & {[0.8245,0.9243]} & {[0.7404,0.9049]} \\
{[0.2596,0.5000]} & {[0.7040,0.8245]} & {[0.6506,0.7889]} & {[0.8245,0.9243]}
\end{array}\right) .
$$

Step 3. Compute weights $w$ of the criteria based on (28) and using (23):

$$
w=\{0.1884,0.2634,0.2439,0.3043\} .
$$

Step 4. We compute the performance of each alternative using (25), to obtain the interval fuzzy number:

$$
\begin{aligned}
& D_{1}=[0.6050,0.8008], \\
& D_{2}=[0.5921,0.7978], \\
& D_{3}=[0.5509,0.7653], \\
& D_{4}=[0.6439,0.7851] .
\end{aligned}
$$

Step 5. In this step, we apply each possibility measure and determine the achieved results. These are then compared to define the differences between them.

Using the possibility measures (1), (2), (3), and (8), we achieved the results presented in Table 1 . The best alternative to be ranked first is $A 3$. (a) For the possibility measures (4) and (5), the obtained possibility matrix is

$$
\left(\begin{array}{llll}
0.5000 & 0.5198 & 0.6093 & 0.4656 \\
0.4802 & 0.5000 & 0.5878 & 0.4437 \\
0.4122 & 0.3907 & 0.5000 & 0.3413 \\
0.6587 & 0.5563 & 0.5344 & 0.5000
\end{array}\right)
$$

The results presented in Table 2 show $A 4$ is the best alternative and ranks first.

(b) As for the possibility measure (6), the obtained possibility matrix is

$$
\left(\begin{array}{llll}
0.5000 & 0.4802 & 0.4122 & 0.6587 \\
0.5198 & 0.5000 & 0.3907 & 0.5563 \\
0.6093 & 0.5878 & 0.5000 & 0.5344 \\
0.4656 & 0.4437 & 0.3413 & 0.5000
\end{array}\right)
$$


TABle 1: Possibility degrees using (1), (2), (3), and (8).

\begin{tabular}{lcccc}
\hline Alternatives & $A 1$ & $A 2$ & $A 3$ & $A 4$ \\
\hline Weights & 0.2543 & 0.2472 & 0.2693 & 0.2292 \\
Ranking & 2 & 3 & 1 & 4 \\
\hline
\end{tabular}

TABle 2: Possibility degrees using (4) and (5).

\begin{tabular}{lcccc}
\hline Alternatives & $A 1$ & $A 2$ & $A 3$ & $A 4$ \\
\hline Weights & 0.2579 & 0.2510 & 0.2204 & 0.2708 \\
Ranking & 2 & 3 & 4 & 1 \\
\hline
\end{tabular}

TABle 3: Possibility degrees using (6).

\begin{tabular}{lcccc}
\hline Alternatives & $A 1$ & $A 2$ & $A 3$ & $A 4$ \\
\hline Weights & 0.2543 & 0.2472 & 0.2693 & 0.2292 \\
Ranking & 2 & 3 & 1 & 4 \\
\hline
\end{tabular}

TABle 4: Possibility degrees using (7).

\begin{tabular}{lcccc}
\hline Alternatives & $A 1$ & $A 2$ & $A 3$ & $A 4$ \\
\hline Weights & 0.2535 & 0.2531 & 0.2569 & 0.2366 \\
Ranking & 2 & 3 & 1 & 4 \\
\hline
\end{tabular}

The results presented in Table 3 show $A 3$ is the best alternative and ranks first.

(c) For the possibility measure (7), the obtained possibility matrix is

$$
\left(\begin{array}{llll}
0.5000 & 0.4941 & 0.4840 & 0.5634 \\
0.5059 & 0.5000 & 0.4789 & 0.5522 \\
0.5211 & 0.5160 & 0.5000 & 0.5458 \\
0.4542 & 0.4478 & 0.4366 & 0.5000
\end{array}\right) .
$$

Table 4 shows that the best alternative is $A 3$ achieving the first rank.

(d) For the possibility measure (9), the obtained possibility matrix is

$$
\left(\begin{array}{cccc}
0.5000 & 0.4810 & 0.4253 & 0.6204 \\
0.5190 & 0.5000 & 0.4103 & 0.5474 \\
0.5897 & 0.5747 & 0.5000 & 0.5296 \\
0.4704 & 0.4526 & 0.3796 & 0.5000
\end{array}\right)
$$

Table 5 shows that the best alternative is $A 3$ that ranks first.

(e) For possibility measure (10), the obtained possibility matrix is

$$
\left(\begin{array}{llll}
0.5000 & 0.4605 & 0.3297 & 0.7883 \\
0.5395 & 0.5000 & 0.2914 & 0.6111 \\
0.7086 & 0.6703 & 0.5000 & 0.5684 \\
0.4316 & 0.3889 & 0.2117 & 0.5000
\end{array}\right) .
$$

TABle 5: Possibility degrees using (9).

\begin{tabular}{lcccc}
\hline Alternatives & $A 1$ & $A 2$ & $A 3$ & $A 4$ \\
\hline Weights & 0.2522 & 0.2481 & 0.2662 & 0.2335 \\
Ranking & 2 & 3 & 1 & 4 \\
\hline
\end{tabular}

TABLE 6: Possibility degrees using (10).

\begin{tabular}{lcccc}
\hline Alternatives & $A 1$ & $A 2$ & $A 3$ & $A 4$ \\
\hline Weights & 0.2565 & 0.2452 & 0.2873 & 0.2110 \\
Ranking & 2 & 3 & 1 & 4 \\
\hline
\end{tabular}

TABLE 7: Possibility degrees using (12).

\begin{tabular}{lcccc}
\hline Alternatives & $A 1$ & $A 2$ & $A 3$ & $A 4$ \\
\hline Weights & 0.2511 & 0.2533 & 0.2557 & 0.2399 \\
Ranking & 3 & 2 & 1 & 4 \\
\hline
\end{tabular}

TABLE 8: Alternatives ranking order for different possibility measures under IFN.

\begin{tabular}{lcc}
\hline Possibility measure & Ranking & Best alternative \\
\hline (1), (2), (3), and (8) & $A 3>A 1>A 2>A 4$ & $A 3$ \\
(4) and (5) & $A 4>A 1>A 2>A 3$ & $A 4$ \\
$(6)$ & $A 3>A 1>A 2>A 4$ & $A 3$ \\
$(7)$ & $A 3>A 1>A 2>A 4$ & $A 3$ \\
$(9)$ & $A 3>A 1>A 2>A 4$ & $A 3$ \\
$(10)$ & $A 3>A 1>A 2>A 4$ & $A 3$ \\
$(12)$ & $A 3>A 2>A 1>A 4$ & $A 3$ \\
\hline
\end{tabular}

Table 6 shows that the best alternative that ranks first is $A 2$.

(f) For the possibility measure (12), the obtained possibility matrix is

$$
\left(\begin{array}{llll}
0.5000 & 0.4938 & 0.4872 & 0.5327 \\
0.5062 & 0.5000 & 0.4939 & 0.5395 \\
0.5061 & 0.5128 & 0.5000 & 0.5491 \\
0.4509 & 0.4605 & 0.4673 & 0.5000
\end{array}\right) .
$$

Table 7 shows that the best alternative is $A 3$ that clearly ranks first.

Table 8 presents a comparison of the obtained results applying different possibility measures under intuitionistic fuzzy sets and shows the alternatives ranking results. We remark that the possibility measures (4) and (5) gave the same best alternative $A 4$ and the worst alternative $A 3$. However using formulas (1), (2), (3), (6), (7), (8), (9), (10), and (12) the best alternative is $A 3$ and the worst alternative is $A 4$. These results show that the measures (4) and (2) are different, although they are demonstrated to be equivalent (the operators lead to value 1) in [17], but they do not produce the same result.

5.2. Application of Possibility Measures of IVIFS in Decision Making Problem. We apply possibility measures of IVIFS 
TABLE 9: Ranking IVIFSs alternatives using possibility measure (16).

\begin{tabular}{lcccc}
\hline Alternatives & $A 1$ & $A 2$ & $A 3$ & $A 4$ \\
\hline Weights & 0.2111 & 0.2161 & 0.2540 & 0.3200 \\
Ranking & 4 & 3 & 2 & 1 \\
\hline
\end{tabular}

TABLE 10: Ranking IVIFSs alternatives using possibility measures (15).

\begin{tabular}{lcccc}
\hline Alternatives & $A 1$ & $A 2$ & $A 3$ & $A 4$ \\
\hline Weights & 0.2469 & 0.2401 & 0.2429 & 0.2640 \\
Ranking & 2 & 4 & 3 & 1 \\
\hline
\end{tabular}

presented in Section 3.2 to rank IVIFS data sets described in Section 5. It is worth reminding that there are four alternatives $A 1, A 2, A 3$, and $A 4$ and four criteria. We use the IVIF matrix of alternatives (27) and the following criteria's weight: $w_{j}=[0.13,0.17,0.39,0.31]$ given in [9].

5.2.1. Case 1: Application of Interval-Valued Intuitionistic Fuzzy Weighted Geometric (IVIFWG) Operator (13). The possibility measures are applied in two cases. In each case an aggregation operator is also applied to the matrix (27).

Step 1. Compute the comprehensive evaluation of each investment (alternative) using the geometric weighted average operator (13) to aggregate the evaluation of each alternative. Thus, we transform the IVIFS decision matrix to IVIFs for each alternative presented as follows:

$$
\begin{aligned}
& D_{1}=[0.4760,0.5970],[0.1915,0.3926], \\
& D_{2}=[0.4211,0.6454],[0.2260,0.3546], \\
& D_{3}=[0.4057,0.6112],[0.1632,0.2833], \\
& D_{4}=[0.5081,06389],[0.2007,0.3016] .
\end{aligned}
$$

Step 2. Each possibility measure presented in Section 3.2 is applied to the obtained IVIFNs: $D_{1}, D_{2}, D_{3}, D_{4}$.

(a) For the possibility degree (16), the obtained possibility matrix is

$$
\left(\begin{array}{llll}
0.5000 & 0.4671 & 0.3840 & 0.1823 \\
0.5443 & 0.5000 & 0.3844 & 0.1647 \\
0.6142 & 0.6210 & 0.5000 & 0.3131 \\
0.6869 & 0.8353 & 0.8177 & 0.5000
\end{array}\right)
$$

Table 9 presents the obtained results and shows that the best alternative is $A 4$.

(b) For possibility measure (15), the obtained possibility degree matrix is

$$
\left(\begin{array}{llll}
0.5000 & 0.5264 & 0.5183 & 0.4185 \\
0.4976 & 0.5000 & 0.4918 & 0.3921 \\
0.5087 & 0.5063 & 0.5000 & 0.4003 \\
0.5510 & 0.5597 & 0.5573 & 0.5000
\end{array}\right)
$$

Table 10 presents the obtained results and shows that the best alternative is $A 4$.
TABLE 11: Ranking IVFISs alternatives using possibility measure (17).

\begin{tabular}{lcccc}
\hline Alternatives & $A 1$ & $A 2$ & $A 3$ & $A 4$ \\
\hline Weights & 0.2627 & 0.2654 & 0.2105 & 0.2614 \\
Ranking & 2 & 1 & 4 & 3 \\
\hline
\end{tabular}

TABLE 12: Ranking IVFISs alternatives using possibility measure (20).

\begin{tabular}{lcccc}
\hline Alternatives & $A 1$ & $A 2$ & $A 3$ & $A 4$ \\
\hline Weights & 0.2254 & 0.2448 & 0.2613 & 0.2686 \\
Ranking & 4 & 3 & 2 & 1 \\
\hline
\end{tabular}

TABLE 13: Ranking order of alternatives for each possibility measure using IVIFS.

\begin{tabular}{lcc}
\hline Possibility measures & Ranking & Best alternative \\
\hline$(15)$ & $A 4>A 1>A 3>A 2$ & $A 4$ \\
$(16)$ & $A 4>A 3>A 2>A 1$ & $A 4$ \\
$(17)$ & $A 2>A 1>A 4>A 3$ & $A 2$ \\
$(20)$ & $A 4>A 3>A 2>A 1$ & $A 4$ \\
\hline
\end{tabular}

(c) For the possibility measure (17), the obtained possibility matrix is

$$
\left(\begin{array}{llll}
0.5000 & 0.5075 & 0.6501 & 0.4944 \\
0.4925 & 0.5000 & 0.6635 & 0.5285 \\
0.3365 & 0.3499 & 0.5000 & 0.3401 \\
0.6599 & 0.4715 & 0.5056 & 0.5000
\end{array}\right)
$$

The obtained results are presented in Table 11 showing that the best alternative is $A 2$.

(d) For the possibility measure (20), the obtained possibility matrix is

$$
\left(\begin{array}{llll}
0.5000 & 0.4446 & 0.3856 & 0.3740 \\
0.5554 & 0.5000 & 0.4570 & 0.4256 \\
0.5430 & 0.6144 & 0.5000 & 0.4778 \\
0.5222 & 0.5744 & 0.6260 & 0.5000
\end{array}\right)
$$

The obtained results are presented in Table 12 showing that the best alternative is $A 4$.

Table 13 presents all the obtained results applying different possibility methods using the interval-valued intuitionistic fuzzy sets and shows the alternatives ranking results. We remark that the possibility formulas (15), (16), and (20) provide the same best alternative $A 4$. However (17) provides the best alternative $A 2$.

5.2.2. Case 2: Application of Optimal Aggregated IntervalValued Intuitionistic Fuzzy Sets (14). Using the optimal aggregated operator (14) to IVIF decision matrix, we obtain 
TABLE 14: Ranking IVFSs using possibility degree (16).

\begin{tabular}{lcccc}
\hline Alternatives & $A 1$ & $A 2$ & $A 3$ & $A 4$ \\
\hline Weights & 0.2256 & 0.2352 & 0.2779 & 0.2599 \\
Ranking & 4 & 3 & 1 & 2 \\
\hline
\end{tabular}

TABLE 15: Ranking IVFSs using possibility measure (15).

\begin{tabular}{lcccc}
\hline Alternatives & $A 1$ & $A 2$ & $A 3$ & $A 4$ \\
\hline Weights & 0.2369 & 0.2322 & 0.2557 & 0.2629 \\
Ranking & 3 & 4 & 2 & 1 \\
\hline
\end{tabular}

four interval-valued intuitionistic fuzzy numbers (IVIFNs) representing the alternatives as follows:

$$
\begin{aligned}
& \widetilde{\alpha_{1}}=[0.4831,0.6089],[0.1850,0.3800], \\
& \widetilde{\alpha_{2}}=[0.4400,0.6520],[0.2170,0.3480], \\
& \widetilde{\alpha_{3}}=[0.4840,0.6450],[0.1560,0.2730], \\
& \widetilde{\alpha_{4}}=[0.5400,0.6530],[0.1950,0.2950] .
\end{aligned}
$$

(a) For the possibility measure (16), the obtained possibility degree matrix is

$$
\left(\begin{array}{llll}
0.5000 & 0.4717 & 0.3595 & 0.3758 \\
0.5366 & 0.5000 & 0.3682 & 0.4177 \\
0.6329 & 0.6403 & 0.5000 & 0.5611 \\
0.4358 & 0.5818 & 0.6008 & 0.5000
\end{array}\right)
$$

The alternatives weight $W_{i}$ is computed using (26) and then ranked in a decreasing order. The results are displayed in Table 14 showing that the best alternative that ranks first is $A_{3}$.

(b) For possibility measure (15), the obtained possibility degree matrix is

$$
\left(\begin{array}{llll}
0.5000 & 0.5188 & 0.4308 & 0.3938 \\
0.5000 & 0.5000 & 0.4120 & 0.3750 \\
0.5525 & 0.5525 & 0.5000 & 0.4630 \\
0.5168 & 0.5693 & 0.5693 & 0.5000
\end{array}\right)
$$

We compute the weight $W_{i}$ of the alternative using (26) and we rank $W_{i}$ in a decreasing order. The results are shown in Table 15 revealing that the best alternative is $A 4$ which ranks first.

(c) For possibility measures (17), the obtained possibility degree matrix is

$$
\left(\begin{array}{llll}
0.5000 & 0.5000 & 0.5767 & 0.4578 \\
0.5000 & 0.5000 & 0.6123 & 0.5035 \\
0.3877 & 0.4233 & 0.5000 & 0.3713 \\
0.6287 & 0.4965 & 0.5422 & 0.5000
\end{array}\right)
$$

TABLE 16: Ranking IVFSs using possibility degree (17).

\begin{tabular}{lcccc}
\hline Alternatives & $A 1$ & $A 2$ & $A 3$ & $A 4$ \\
\hline Weights & 0.2529 & 0.2596 & 0.2235 & 0.2639 \\
Ranking & 3 & 2 & 4 & 1 \\
\hline
\end{tabular}

TABLE 17: Ranking IVFISs alternatives using possibility measure (20).

\begin{tabular}{lcccc}
\hline Alternatives & $A 1$ & $A 2$ & $A 3$ & $A 4$ \\
\hline Weights & 0.2240 & 0.2392 & 0.2695 & 0.2673 \\
Ranking & 4 & 3 & 1 & 2 \\
\hline
\end{tabular}

TABLE 18: Alternatives ranking order for each possibility measure using IVIFS.

\begin{tabular}{lcc}
\hline Possibility measures & Ranking & Best alternative \\
\hline$(15)$ & $A 4>A 3>A 1>A 2$ & $A 4$ \\
$(16)$ & $A 3>A 4>A 2>A 1$ & $A 3$ \\
$(17)$ & $A 4>A 2>A 1>A 3$ & $A 4$ \\
$(20)$ & $A 3>A 4>A 2>A 1$ & $A 3$ \\
\hline
\end{tabular}

We compute the weights $W_{i}$ of the alternatives using (26) and we rank $W_{i}$ in a decreasing order. The results are displayed in Table 16 showing that the best alternative that rank first is $A 4$.

(d) For possibility measure (20), the obtained possibility matrix is

$$
\left(\begin{array}{llll}
0.5000 & 0.4485 & 0.3685 & 0.3705 \\
0.5515 & 0.5000 & 0.4082 & 0.4105 \\
0.5918 & 0.6315 & 0.5000 & 0.5113 \\
0.4887 & 0.5895 & 0.6295 & 0.5000
\end{array}\right)
$$

The obtained results are presented in Table 17 showing that the best alternative is $A 3$.

Table 18 presents the results of all applied possibility measures using the interval-valued intuitionistic fuzzy sets and shows the alternatives ranking results. We remark that the possibility formulas (15) and (17) provide the same best alternative A4. However (16) and (20) provide the best alternative $A 3$. We note that the latter is the worst alternative using (17).

\section{Conclusion}

In this study, we presented different formulas of possibility measures. The formulas exist in literature with IFN and IVIFN. We also presented an MCDM method from the literature. We gave an illustrative examples for applications of different possibility measures and compared their results. First we used an MCDM matrix with intuitionistic fuzzy numbers and then an MCDM matrix with IVIFNs. The values of the latter are aggregated with an aggregation operator in two cases. In each case a different aggregation operator was used. Thus, the appropriate possibility measures are applied. 
The results show that the ranked alternatives can be different for each possibility measure, even though some of these measures have already been demonstrated to be equivalent in the literature.

\section{Appendix}

\section{Intuitionistic Fuzzy Sets}

Intuitionistic fuzzy sets are introduced by Atanassov [16] who defined a degree of membership $\mu$, a degree of nonmembership $\nu$, and a degree of hesitation $\pi$ of an element $x$ of an IFS.

$A=\left(\mu_{A}, \nu_{A}\right)$ denotes an intuitionistic fuzzy number if $\mu_{A}$ and $\nu_{A}$ are fuzzy numbers with $\nu_{A} \leq \mu_{A}^{c}$, where $\mu_{A}^{c}$ denotes the complement of $\mu_{A}$.

If $X$ is a discourse universe and $A$ a set in $X$, then

$$
A=\left\{\left\langle x, \mu_{A}(x), v_{A}(x)\right\rangle \mid x \in X\right\}
$$

with the conditions $0 \leq \mu_{A}(x) \leq 1,0 \leq v_{A}(x) \leq 1,0 \leq$ $\mu_{A}(x)+\nu_{A}(x) \leq 1$, and $\pi_{A}(x)=1-\mu_{A}(x)-v_{A}(x)$. Also for each $x \in X, 0 \leq \Pi_{A}(x) \leq 1$.

\section{Competing Interests}

The authors declare that they have no competing interests.

\section{Acknowledgments}

The authors would like to acknowledge the financial support of this work by grants from General Direction of Scientific Research (DGRST), Tunisia, under the ARUB program. They would like to thank Mr. Abdelmajid Dammak for his proofreading and correction of the English of the paper.

\section{References}

[1] J. H. Park, I. Y. Park, Y. C. L. Kwun, and X. Tan, "Extension of the TOPSIS method for decision making problems under intervalvalued intuitionistic fuzzy environment," Applied Mathematical Modelling, vol. 35, no. 5, pp. 2544-2556, 2011.

[2] D. G. Park, Y. C. Kwun, J. H. Park, and I. Y. Park, "Correlation coefficient of interval-valued intuitionistic fuzzy sets and its application to multiple attribute group decision making problems," Mathematical and Computer Modelling, vol. 50, no. 9-10, pp. 1279-1293, 2009.

[3] J. Ye, "Multicriteria fuzzy decision-making method using entropy weights-based correlation coefficients of intervalvalued intuitionistic fuzzy sets," Applied Mathematical Modelling, vol. 34, no. 12, pp. 3864-3870, 2010.

[4] H. Zhang and L. Yu, "MADM method based on cross-entropy and extended TOPSIS with interval-valued intuitionistic fuzzy sets," Knowledge-Based Systems, vol. 30, pp. 115-120, 2012.

[5] Z.-S. Xu, "Methods for aggregating interval-valued intuitionistic fuzzy information and their application to decision making," Control and Decision, vol. 22, no. 2, pp. 215-219, 2007.

[6] Z.-S. Xu and J. Chen, "Approach to group decision making based on interval-valued intuitionistic judgment matrices," Systems Engineering-Theory \& Practice, vol. 27, no. 4, pp. 126-133, 2007.
[7] X. Zhang, G. Yue, and Z. Teng, "Possibility degree of intervalvalued intuitionistic fuzzy numbers and its application," in Proceedings of the International Symposium on Information Processing (ISIP '09), pp. 33-36, Huangshan, China, 2009.

[8] J. Wu, Q. Cao, and H. Li, "An approach for MADM problems with interval-valued intuitionistic fuzzy sets based on nonlinear functions," Technological and Economic Development of Economy, vol. 22, no. 3, pp. 336-356, 2016.

[9] Z. Wang, K. W. Li, and W. Wang, "An approach to multiattribute decision making with interval-valued intuitionistic fuzzy assessments and incomplete weights," Information Sciences, vol. 179, no. 17, pp. 3026-3040, 2009.

[10] S. C. Onar, B. Oztaysi, I. Otay, and C. Kahraman, "Multiexpert wind energy technology selection using interval-valued intuitionistic fuzzy sets," Energy, vol. 90, part 1, pp. 274-285, 2015.

[11] Z. Xu and R. R. Yager, "Some geometric aggregation operators based on intuitionistic fuzzy sets," International Journal of General Systems, vol. 35, no. 4, pp. 417-433, 2006.

[12] Z. Xu, "Intuitionistic fuzzy aggregation operators," IEEE Transactions on Fuzzy Systems, vol. 15, no. 6, pp. 1179-1187, 2007.

[13] C.-P. Wei and X. Tang, "Possibility degree method for ranking intuitionistic fuzzy numbers," in Proceedings of the $3 \mathrm{rd}$ IEEE/WIC/ACM International Conference on Web Intelligence and Intelligent Agent Technology (WI-IAT '10), pp. 142-145, IEEE, Toronto, Canada, August 2010.

[14] Z. S. Xu and Q. L. Da, "Possibility degree method for ranking interval numbers and its application," Journal of Systems Engineering, vol. 18, pp. 67-70, 2003.

[15] Y.-M. Wang, J.-B. Yang, and D.-L. Xu, "Interval weight generation approaches based on consistency test and interval comparison matrices," Applied Mathematics and Computation, vol. 167, no. 1, pp. 252-273, 2005.

[16] K. T. Atanassov, "Intuitionistic fuzzy sets," Fuzzy Sets and Systems, vol. 20, no. 1, pp. 87-96, 1986.

[17] F. Gao, "Possibility degree and comprehensive priority of interval numbers," Systems Engineering-Theory \& Practice, vol. 33, no. 8, pp. 2033-2040, 2013.

[18] Y.-Y. Liu and Y.-J. Lv, "A multiple attribute decision making method with interval rough numbers based on the possibility degree," in Proceedings of the 10th International Conference on Natural Computation (ICNC '14), pp. 407-411, IEEE, Xiamen, China, August 2014.

[19] L. A. Zadeh, "Fuzzy sets as a basis for a theory of possibility," Fuzzy Sets and Systems, vol. 1, no. 1, pp. 3-28, 1978.

[20] H. Yuan and Y. Qu, "Model for conflict resolution with preference represented as interval numbers," Proceedings of the MATEC Web of Conferences, 2015.

[21] G. Facchinetti, R. G. Ricci, and S. Muzzioli, "Note on ranking fuzzy triangular numbers," International Journal of Intelligent Systems, vol. 13, no. 7, pp. 613-622, 1998.

[22] Q. L. Da and X. W. Liu, "Interval number linear programming and its satisfactory solution," Systems Engineering Theory \& Practice, vol. 19, pp. 3-7, 1999.

[23] C.-P. Wei and X. Tang, "Possibility degree method for ranking intuitionistic fuzzy numbers," Journal of Systems Engineering, vol. 18, pp. 67-70, 2003.

[24] Z. S. Xu and Q. L. Da, "The uncertain ow a operator," International Journal of Intelligent Systems, vol. 17, no. 6, pp. 569-575, 2002. 
[25] Z. S. Xu and Q. L. Da, "A possibility based method for priorities of interval judjment matrices," Chinese Journal of Management Science, vol. 11, pp. 63-65, 2003.

[26] D. Q. Li and Y. D. Gu, "methods for ranking interval number based on possibility degree," Journal of Systems Engineering, vol. 23, pp. 223-226, 2008.

[27] J. B. Lan, L. J. Cao, and J. Lin, "Method for rinking interval numbers on two-dimensional priority degree," Journal of Chongqing Institute of Technology: Natural Science Edition, vol. 21, pp. 6366, 2007.

[28] T.-Y. Chen, "Interval-valued intuitionistic fuzzy QUALIFLEX method with a likelihood-based comparison approach for multiple criteria decision analysis," Information Sciences, vol. 261, pp. 149-169, 2014.

[29] K. Atanassov and G. Gargov, "Interval valued intuitionistic fuzzy sets," Fuzzy Sets and Systems, vol. 31, no. 3, pp. 343-349, 1989.

[30] G. W. Wei and X. R. Wang, "Some geometric aggregation operators on interval-valued intuitionistic fuzzy sets and their application to group decision making," in Proceedings of the International Conference on Computational Intelligence and Security (ICCIS '07), pp. 495-499, Harbin, China, December 2007.

[31] Z. S. Xu and J. Chen, "On geometric aggregation over intervalvalued intuitionistic fuzzy information," in Proceedings of the 4th International Conference on Fuzzy Systems and Knowledge Discovery (FSKD '07), vol. 2, pp. 466-471, Haikou, China, August 2007.

[32] Y. He, H. Chen, L. Zhou, J. Liu, and Z. Tao, "Generalized interval-valued Atanassov's intuitionistic fuzzy power operators and their application to group decision making," International Journal of Fuzzy Systems, vol. 15, no. 4, pp. 401-411, 2013.

[33] S. Wan and J. Dong, "A possibility degree method for intervalvalued intuitionistic fuzzy multi-attribute group decision making," Journal of Computer and System Sciences, vol. 80, no. 1, pp. 237-256, 2014.

[34] F. Dammak, L. Baccour, and A. M. Alimi, "The impact of criterion weights techniques in topsis method of multi-criteria decision making in crisp and intuitionistic fuzzy domains," in Proceedings of the IEEE International Conference on Fuzzy Systems (FUZZ-IEEE '15), pp. 1-8, Istanbul, Turkey, August 2015. 

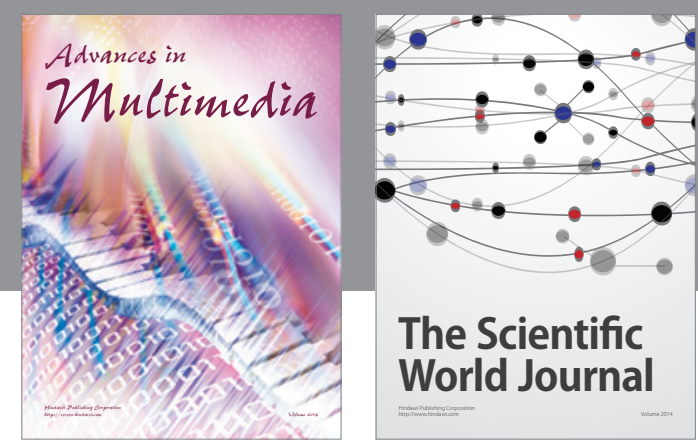

The Scientific World Journal
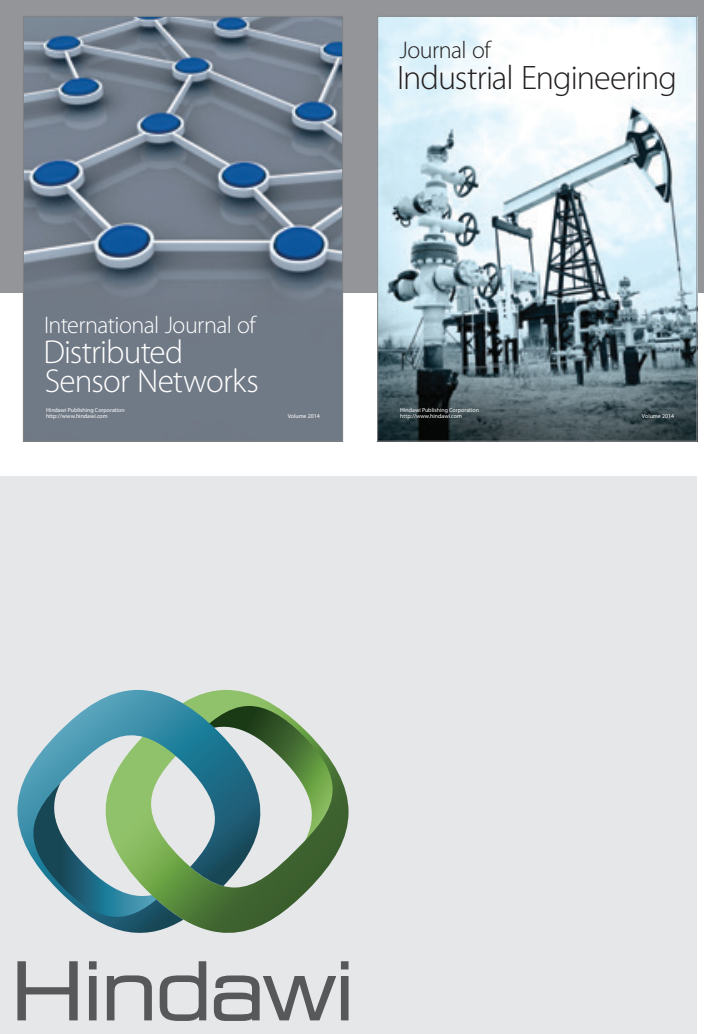

Submit your manuscripts at

http://www.hindawi.com

\section{Computer Networks} and Communications
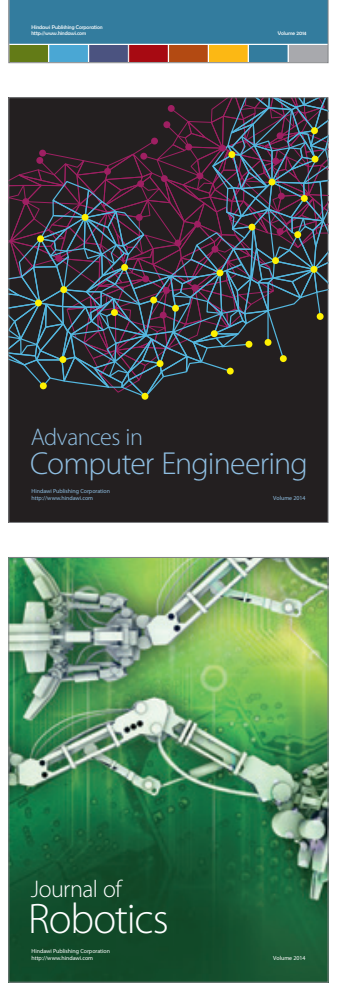
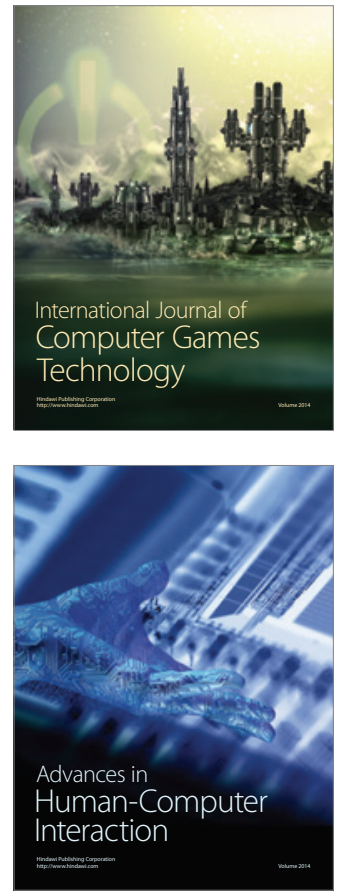
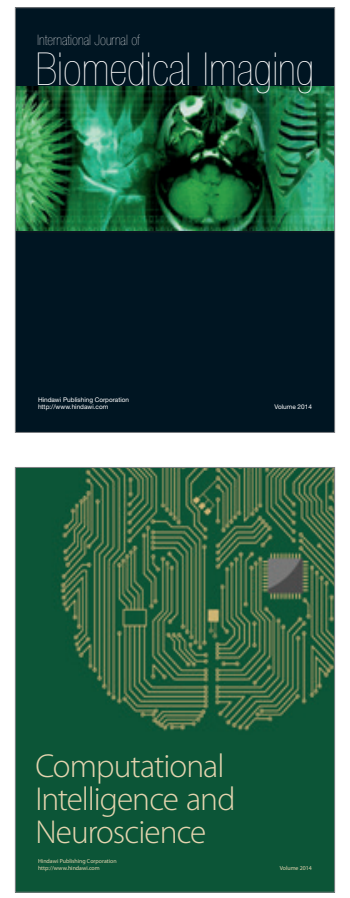
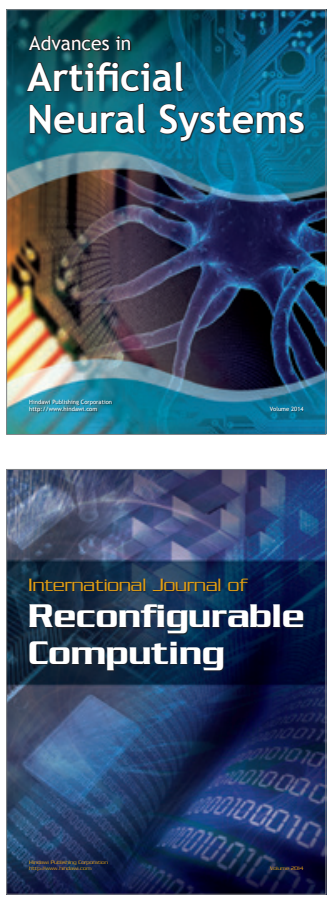
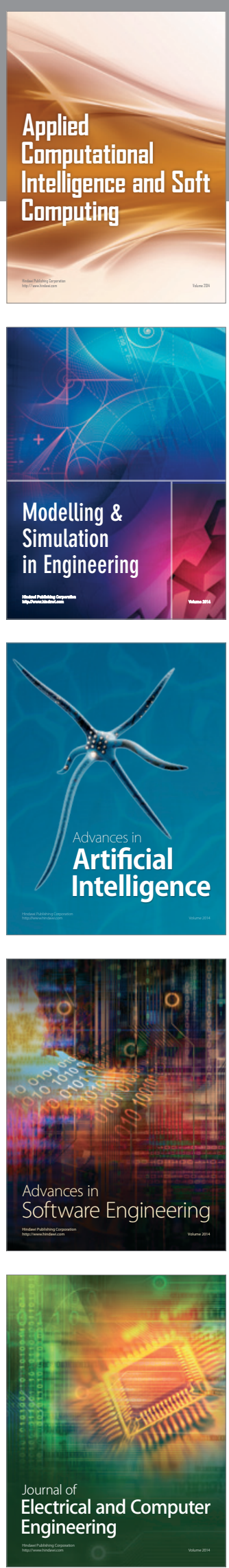